Federal Reserve Bank of Minneapolis

Research Department

\title{
A Model of Family Labor Supply in War and Peace
}

R. Anton Braun and Ellen R. McGrattan*

Working Paper 527

April 1994

*Both, Federal Reserve Bank of Minneapolis. Correspondence to: Research Department, P. O. Box 291, Federal Reserve Bank of Minneapolis, Minneapolis, MN 55480-0291. We thank seminar participants at the 1993 NBER summer institute, the University of Houston, the Federal Reserve Bank of Dallas, the University of Texas, the University of Washington, the University of British Columbia, and the University of Pittsburgh for their comments. The second author thanks the NSF and the Minnesota Supercomputer Institute for their support. The views expressed herein are those of the authors and not necessarily those of the Federal Reserve Bank of Minneapolis or the Federal Reserve System. 


\section{Introduction}

Business cycle models with household production have been shown to capture some of the principal features of aggregate labor market fluctuations. ${ }^{1}$ However, these models predict that we should observe significant reallocations of total hours between the market and home sector over the course of the business cycle. For the U.S., the most likely source of this reallocation is females. Thus far, business cycle models with household production have not been put to the more stringent test of matching movements in male and female hours.

In this paper, we develop a model of household production that distinguishes hours per worker and employment of men and women. The distinction between hours and employment is important since hours per worker show little variation over the business cycle while employment variability is large. If we condition on this property of the data, home production models predict a large reallocation of bodies between the market and home sector over the course of the business cycle. The distinction between males and females is important because males in the U.S. do very little home production while females do a significant amount of home production. Data from the PSID summarized in Morgan (1978) indicates that husbands devote on average 6 hours per week to home production. For working wives with children under 12 , hours worked in the home sector averages 28 hours a week and increases with the size of the family. Homework by husbands actually declines as the size of the household increases. Hours devoted to home production by nonworking wives averages 38 hours per week. These patterns suggest that the contribution of men to home production is negligible. In terms of market employment, the data show a larger cyclical response for women than for men. For instance, Clark and Summers (1981) find that the cyclical response of women under 35 is more than twice as large as for prime-aged males.

These facts lead us to explicitly model the joint labor supply decisions of married men and women. Our model is sexist because we assume that the labor input of wives can be used in both market and homework while the labor input of their husbands is only used in the market. Thus, participation of women in the market is less than 100 percent because

1 See, for example, Benhabib, Rogerson, and Wright (1991), Greenwood and Hercowitz (1991), and McGrattan, Rogerson, and Wright (1993). 
they have two productive uses of their time. This is a key difference between our model of family labor supply and that of Cho and Rogerson (1988) who abstract from home production. In the Cho and Rogerson (1988) model, female labor participation rates are less than 100 percent because wives are assumed to be less productive in market activities than their husbands. In our model, husbands and wives are equally productive in the market sector.

We consider the responses of male and female labor supply to two types of shocks. First, we estimate a Markov regime switching process for government purchases and conscription and simulate the effects of a large war on employment and hours worked by married women and men. Our model reproduces both the large increase in participation of married women during World War II and its subsequent decline following the war as men returned home. Second, we consider the response of labor supply to technology shocks in the home and market sectors, which are important sources of cyclical variation during the post World War II period. Our simulations indicate that the model's predictions are consistent with the measured patterns of employment and hours worked for married women in postwar U.S. data. The model accounts for the fact that hours worked by married women is more variable than hours worked by their spouses and reproduces the variability and cyclical pattern of employment for married women. When we aggregate over bodies and hours per worker, the model produces plausible predictions for aggregate hours too. From this we conclude that there are large reallocations of married women between the home and market sectors and that these shifts are of the magnitude predicted by aggregate models of home production.

Our model also has implications for the variability of aggregate employment and hours per worker. In other work, Kydland and Prescott (1991) and Cho and Cooley (1994) consider models that produce too little variability in employment and hours per worker. We find that once household production and fluctuations in government purchases are included, our model accounts for the measured variability in employment and hours per worker in U.S. data.

We describe the model and equilibrium concept that we use in Section 2. In Section 3 , we describe the numerical methods used to compute an equilibrium. In Section 4 , we discuss a parameterization used when simulating our model economy. Our findings are 
reported in Section 5; in particular, we compare predictions of the model to the U.S. data during World War II and after. Conclusions are in Section 6.

\section{The Model Economy}

Our model economy is inhabited by a continuum of ex-ante identical households. Each household has two members. Both members enjoy consumption of goods produced in the market, goods produced in the home, and leisure. The preferences of household $i$ are given by

$$
E \sum_{t=0}^{\infty} \beta^{t}\left\{u\left(c_{i m}[t], x_{i m}[t]\right)+u\left(c_{i f}[t], x_{i f}[t]\right)-v\left(h_{i m}[t], h_{i f}[t], n_{i}[t]\right)\right\}, \quad 0<\beta<1
$$

where $c_{i j}[t]$ is consumption of market goods by member $j$ at date $t, j=m$ or $f, x_{i j}[t]$ is consumption of home-produced goods by member $j$ at date $t, h_{i j}[t]$ are hours that member $j$ works in the market in $t$, and $n_{i}[t]$ are hours spent in home production in $t$. The function $v$ could have cross-products between hours of the two members to allow for the possibility that leisure of the two are complements.

We use the subscripts $m$ and $f$ to denote male and female since we assume two key distinctions between the family members. First, we assume that only member $f$ 's labor input is used in production of home goods. Second, as will be shown later, only member $m$ is conscripted. Males who are not conscripted can use their time allocation for market work or leisure. Females can use their time allocation for market work, homework, or leisure. And because females can use the productive time at home, it will be the case that those females working have husbands working as well. For the U.S. during World War II and the postwar, the demographic group most like our members denoted $f$ are married women whose husbands are employed. However, one could also interpret the family structure here more broadly if we assume that member $m$ is any member of the family employed full-time in market work and member $f$ is another family member that works at home or in the market or both.

The labor supply decisions for the household include participation for member $f$, number of hours to work, and how many hours to allocate to home and market for an employed member $f$. Another determinant of labor supply is conscription during periods 
of war. We assume that military employment is not a choice. That is, in times of war, a certain fraction of the population is conscripted. Therefore, there are at least two types of families: those with member $m$ in the civilian population and those with member $m$ in the armed forces. Non-military families will be distinguished by their employment choice; some families have both members working in the market and some have only one member working in the market.

Because of the participation decision for $f$, the consumption set for the household optimization problem is not convex. We follow Cho and Rogerson (1988) and assume that optimal allocations involve lotteries to determine employment. In essence, we assume that insurance markets exist that allow families to smooth consumption. In the aggregate, there will be a certain fraction of families with members in the military and a certain fraction of civilian families with the second member doing both market and homework. In particular, the social optimum can be found by solving the following optimization problem: choose functions for market consumption $c_{j z}$, hours of work in the market $h_{j z}$, hours of work in the home $n_{j}$, the participation rate $p$, market capital $k_{m}$, and home capital $k_{j n}$ for $j \in\{1,2\}$ and $z \in\{m, f\}$ to maximize

$$
\begin{gathered}
E \sum_{t} \beta^{t}(1-a[t])\left\{p[t]\left\{u\left(c_{1 m}[t], x_{1 m}[t]\right)+u\left(c_{1 f}[t], x_{1 f}[t]\right)-v\left(h_{1 m}[t], h_{1 f}[t], n_{1}[t]\right)\right\}\right. \\
\left.+(1-p[t])\left\{u\left(c_{2 m}[t], x_{2 m}[t]\right)+u\left(c_{2 f}[t], x_{2 f}[t]\right)-v\left(h_{2 m}[t], 0, n_{2}[t]\right)\right\}\right\} \\
+a[t]\left\{u\left(c_{3 f}[t], x_{3 f}[t]\right)-v\left(0,0, n_{3}[t]\right)\right\}
\end{gathered}
$$

subject to

$$
\begin{aligned}
(1-a[t])\left\{p[t] c_{1 m}[t]\right. & +p[t] c_{1 f}[t]+(1-p[t]) c_{2 m}[t]+(1-p[t]) c_{2 f}[t] \\
& +\kappa(p[t])\}+a[t] c_{3 f}[t]+g[t]+i[t] \leq z_{1}[t] F\left(k_{m}[t], H_{m}[t]\right) \\
x_{1 m}[t]+x_{1 f}[t] & =z_{2}[t] G\left(k_{1 n}[t], n_{1}[t]\right) \\
x_{2 m}[t]+x_{2 f}[t] & =z_{2}[t] G\left(k_{2 n}[t], n_{2}[t]\right) \\
x_{3 f}[t] & =z_{2}[t] G\left(k_{3 n}[t], n_{3}[t]\right) \\
k[t+1] & =(1-\delta) k[t]+i[t] \\
k[t] & =k_{m}[t]+(1-a[t])\left\{p[t] k_{1 n}[t]+(1-p[t]) k_{2 n}[t]\right\}+a[t] k_{3 n}[t] \\
H_{m}[t] & \left.=(1-a[t])\left\{p[t] h_{1 m}[t]+z_{3}[t] p[t] h_{1 f}[t]+(1-p[t]) h_{2 m}[t]\right\}\right) .
\end{aligned}
$$


The objective function is an equal-weighted sum of utilities of the civilian population. The variable $a[t]$ is the fraction of families with member $m$ in the armed forces. The first three terms of the objective function in (1) represent the utility of families with the female (member $f$ ) working (i.e., families of type 1). The fraction of families in this group is $(1-a[t]) p[t]$, where $p[t]$ is the participation rate of females in the civilian population. Since there is no unemployment in this model, the employment rate is equal to the participation rate. The second three terms of the objective function in (1) represent the utility of families with the male working in the market and the female working at home (i.e., families of type $2)$. The fraction of families in this group is $(1-a[t])(1-p[t])$. Notice that the second argument of $v$ for this group is zero, indicating that the market hours of the wife are zero. Finally, the last two terms of the objective function in (1) represent the utility of the type-3 families that have the husband in the army and the wife in home production. We assume that the husband's consumption is part of government consumption rather than private consumption. There are no families with the husband in the army and the wife working in equilibrium.

The resource constraint in (2) ensures that total private market consumption plus government consumption plus investment does not exceed total output of market goods. Market consumption includes expenditures on goods that bring utility and fixed costs if both members of the family work (i.e., $\kappa(p[t])$ ). Equations (3)-(5) are the home production functions for the three families. We assume that the same technology is available to all families. Equation (6) is the capital accumulation equation that relates the total capital stock to total investment. Notice that investment goods are produced in the market. Equations (7) and (8) are identities that relate individual input levels to the aggregate levels of the capital stock $(k)$ and market hours of work $\left(H_{m}\right)$.

In addition to the constraints of (2)-(8), we specify processes for the exogenous state variables. They are: the market technology shock $z_{1}[t]$, the home technology shock $z_{2}[t]$, the shock to female productivity $z_{3}[t]$, government spending $g[t]$, and military employment $a[t]$. The shocks to technology and productivity are assumed to be autoregressive processes that are not necessarily independent of each other. The spending and employment shocks are assumed to depend on a Markov chain with states that indicate the state of war or peace (or stages in between war and peace). 
From the first order conditions of the maximization problem in equations (1)-(8), we can obtain several general characteristics of an equilibrium for this model. First, note that consumption levels of both market and home goods are the same for husbands and wives (i.e., $c_{i m}=c_{i f}$ and $x_{i m}=x_{i f}, i=1,2$ ). This is due to the fact that their utility functions over goods are the same. Second, note that if $v$ is separable in male and female hours, then all men work the same number of hours in the private sector. If their marginal conditions depend on the hours choice of their wives, say because of complementarities in leisure, then this prediction changes. Third, note that if household utility does not depend on consumption of home goods, then men and women are only different if the productivity level of women is not equal to the productivity level of men (i.e., $z_{3} \neq 1$ ). Cho and Rogerson (1988) abstract from household production and set $z_{3 t}<1$ for all $t$. Thus, women would participate less than men in the Cho-Rogerson economy since their labor is less valuable. In our economy with home goods desired, women participate less than men because they have other productive uses of their time. This result holds even if $z_{3 t}=1$ for all $t$.

To determine other predictions of this model for family labor supply, we need to calculate the optimal decision functions for consumption, investment, and employment. We describe numerical methods that can be applied to this task in the next section.

\section{Computation}

To compute equilibrium decision, we use the finite element method as outlined in McGrattan (1993). ${ }^{2}$ To implement the method, we derive the first order conditions of the optimization problem in equations (1)-(8). This derivation yields one intertemporal constraints and twelve intratemporal constraints. We use the intertemporal equation to compute the consumption function for a man whose wife is employed. Then, all other decisions can be determined by way of the intratemporal constraints.

The computational task can be stated as follows. Find the function $c_{1 m}(k, z, s)$ that

\footnotetext{
${ }^{2}$ A technical appendix is available upon request.
} 
satisfies the intertemporal Euler equation

$u_{1}\left(c_{1 m}(k, z, s), x_{1 m}\right)-\beta \sum \pi_{s^{\prime} \mid s} \int u_{1}\left(c_{1 m}\left(k^{\prime}, z^{\prime}, s^{\prime}\right), x_{1 m}^{\prime}\right)\left(1-\delta+F_{1}\left(k_{m}^{\prime}, H_{m}^{\prime}\right)\right) f(\epsilon) d \epsilon=0$

where $k$ is the aggregate capital stock, $z$ is the vector of shocks to technology and productivity, $s$ is the state governing war and peace, $c_{1 m}(k, z, s)$ is consumption of market goods for the male (i.e., member $m$ ) in family-type $1, x_{1 m}$ is a function of $c_{1 m}(s)$ and $s, x_{1 m}^{\prime}, k_{m}^{\prime}$, $H_{m}^{\prime}$ are functions of the state next period, $s^{\prime}$, and $c_{1 m}\left(s^{\prime}\right), \epsilon$ is the disturbance term for the autoregressive technology and productivity shocks, and $f(\cdot)$ is its density function. Values for $x_{1 m}, k_{m}$, and $H_{m}$ are derived from the intratemporal first order conditions reported in Appendix A. In addition to $x_{1 m}, k_{m}$, and $H_{m}$, the intratemporal conditions yield values for all other decisions; the values of these decisions are needed when updating the state vector.

Let $R(k, z, s)=0$ be the residual equation displayed in (9). Assume, for some value of the state vector $[k, z, s]$, that $c_{1 m}(k, z, s)$ can be approximated by the following function,

$$
c_{1 m}(k, z, s) \simeq \sum_{a=1}^{A} \gamma_{a}^{s} N_{a}(k, z)
$$

where $N_{a}(k, z), a=1, \ldots A$ are known basis functions and $\gamma_{a}^{s}$ are constants to be computed. The state $s$ takes on a discrete set of values and is, therefore, not an argument of the basis functions. We use basis functions that are positive on only a small region (i.e., an element) of the domain and everywhere else equal to zero. $N_{a}(k, z)$ is chosen to be a small-order polynomial; in our case, it is linear. The values of the $\gamma_{a}^{s}$ 's used in our approximation are those that satisfy

$$
\iint R(k, z, s ; \gamma) N_{a}(k, z) d k d z=0, \quad a=1, \ldots A .
$$

Thus, the problem is to solve a nonlinear system of equations. We solve the nonlinear system with a Newton method.

One more step is required before simulating the model economy. We must parameterize the model. We describe the values chosen in the next section.

\section{Parameterization of the Model}


In this section, we discuss a parameterization of our model economy. The parameters that need to be set are (a) those governing the Markov process for military employment and expenditures, (b) those of the utility and production functions, (c) those determining the resource costs lost when both members of the family work, and (d) those determining how complementary is leisure between the two members. To obtain the first set of parameters, we use the maximum likelihood estimation procedure of Hamilton (1991). For the second set, we use the maximum likelihood estimates from McGrattan, Rogerson, and Wright (1993). For the last two sets of parameters, we try alternative values since we do not have any econometric estimates.

We start with the parameterization of the law of motion for the fiscal policy variables. During the twentieth century, fluctuations in fiscal policy variables have been dominated by the effects of wars. We model this property of the data by assuming that military employment and government spending have a common finite state Markov component. The Markov process is estimated using data on the fraction of the working population employed in the military. ${ }^{3}$

Assume that military employment in time $t$ has the following representation:

$$
a[t]=s[t]+u[t]
$$

where $s[t]$ takes on $l$ distinct values. Associated with $s[t]$ is the $l \times l$ transition matrix, $\pi_{s^{\prime} \mid s}$, with element $(i, j)$ given by

$$
\pi_{s^{\prime} \mid s}(i, j)=\operatorname{prob}(s[t+1]=i \mid s[t]=j) .
$$

The term $u[t]$ is assumed to be independently and identically distributed normal variable with mean zero and variance $\sigma_{u}^{2}$. We also assume that the econometrician can only observe the sum of $s[t]$ and $u[t]$ and that $s[t]$ and $u[t]$ are independent. Hamilton (1989) describes a procedure for calculating maximum likelihood estimates of $\pi_{s^{\prime} \mid s}$ and $\sigma_{u}^{2}$. In order to evaluate the likelihood function it is necessary to calculate the conditional density for $a[t]$, i.e.,

$$
f(a[t] \mid \Omega[t])=\sum_{i=1}^{m} f(a[t], s[t]=i \mid \Omega[t-1])
$$

\footnotetext{
3 The data sources are described in the appendix.
} 
where $\Omega[t]=(a[t], \Omega[t-1])$ and $s_{0}=1$. Hamilton (1991) describes a generalization of the Kalman filtering algorithm for calculating the conditional densities. Then, the loglikelihood of the data is given by

$$
\sum_{t=1}^{T} \log f(a[t] \mid \Omega[t-1])
$$

The maximum likelihood estimates for a 4-state representation of military employment are presented in Table 1. These estimates use annual data between 1900 and 1985. The $(1,2),(2,1),(2,3),(3,2)$, and $(4,1)$ elements of $\pi$ were constrained to be zero after unconstrained estimation put them on the corner. Standard errors are not reported for the fourth column because these estimates are implied by the other three columns. Not reported in the table is our estimate of $\sigma_{u}^{2}$ which is 1.78 with a standard error of 0.285 .

Using the estimates of Table 1 we can calculate the smoothed probabilities

$$
\operatorname{prob}(s[t]=i \mid \Omega[T]), \quad i=1, \ldots, T .
$$

Figure 1 contains a plot of the data for military expenditures and the smoothed probabilities multiplied by their conditional means. From this plot we see that the estimates predict the wartime peaks for World War I, World War II and the Korean war. On the other hand, this statistical model has more difficulty predicting the magnitude or duration of the Vietnam war and the subsequent decline in military employment after 1970.

For the parameters of utility and production, we use the estimates of McGrattan, Rogerson, and Wright (1993) (MRW). ${ }^{4}$ In Table 2, we report functional forms that we use for utility and production and the parameter estimates. Note that CES functions are used for both utility and production. The elasticity of substitution between market and home goods is reasonably high which indicates a willingness on the part of households to substitute when relative productivities in the market and home change. We also use the MRW estimates of the discount factor and the depreciation rate on capital (assumed to be the same for home and market capital). Their estimate of $\beta$ is 0.991 , which at an annual level is 0.965 . Their estimate of $\delta$ is 0.0223 or 0.0892 for the annual stock.

4 See McGrattan, Rogerson, and Wright (1993) for details about the estimation procedure and for standard errors of the estimates. 
MRW also obtain estimates for the market and home technology shocks. However, these variables depend on other variables in their model (e.g., distortionary tax rates on capital and labor) that are not present here. To keep things simple, we assume that $\left[z_{1}[t], z_{2}[t]\right]$ is an $\operatorname{AR}(1)$ with coefficient matrix equal to 0.95 times the identity matrix. The variances are chosen to get approximately the same variances as estimated by MRW. Since the estimates of MRW imply that the covariance between the two technology shocks is small and insignificant, we set it to zero here.

For now, we set the productivity shock for women constant and equal to one. In Cho and Rogerson (1988), the fact that female productivity is assumed to be lower than male productivity yields the result that all men work and only a fraction of women work. In our model, some women are at home because of home production.

We have no estimate for parameter $d$ in utility of families of type 1. This parameter determines the degree to which leisure of the family members are complements. For the simulations of the next section, we start with a value of -2.2 and experiment with other values. Similarly for $\kappa(p)$, we start with a particular specification $\left(\kappa(p)=0.2 p+0.1 p^{2}\right)$ and then consider alternatives. ${ }^{5}$ These specifications give a steady state level of participation equal to about $45 \%$ which is in the range of rates over our sample.

\section{Findings}

In this section, we use the parameter estimates described in Section 4 to compute an equilibrium and to simulate time series. The results of the simulation are compared to U.S. data to see if the model can capture the wartime and postwar movements in employment and hours of work.

In Figure 2, we plot U.S gross national product and the fraction of families with both the husband and at least one other family member employed as percent deviations from their long-run trends. ${ }^{6}$ The fraction of families with the husband and another employed is comparable to the participation rate $p[t]$ of our model. Notice that the rate is procyclical with the percent deviations almost as large as the percent deviations in output.

\footnotetext{
5 We actually started with a linear specification and had some difficulties computing an equilibrium.

6 The detrending procedure is described in Prescott (1986).
} 
Killingsworth and Heckman (1986) use the results of an ordinary least squares regression of first differences in the female participation rates on a constant and first differences of male unemployment rates to test the hypothesis that female participation is sensitive to cyclical factors. The idea behind their regression is to decompose the trend and cyclical responses. They find that the coefficient on male unemployment rates, which determines the cyclical response, is not significant for many age groups or for the total 16 years and older group. If we redo the exercise with the participation rate as defined above and with GNP rather than the unemployment rate, we find: $\Delta p[t]=0.432(0.196)+0.008(0.002) \Delta y[t]$ with $R^{2}=0.37$ for the sample 1958-1987, where $y[t]$ is equal to gross national product and standard errors are in parentheses. Therefore, unlike the regression results of Killingsworth and Heckman (1986), which are based on the sample 1955-1982, we find a significant cyclical response. We also find a much higher $R^{2}$; the $R^{2}$ reported by Killingsworth and Heckman (1986) for white females, 16 and older, was 0.05 .

In Figure 3, we display percent deviations of GNP and the fraction of families with two or more earners. The latter series is another possible measure for $p[t]$. Notice that the result is the same as with the fraction of families with the husband and another family member employed; participation is procyclical and it fluctuates almost as much as output.

If we compare these observations for the U.S. with predictions of the model, we find that the model produces a similar result. In Figure 4, we plot deviations for simulated output and participation. These series were simulated assuming that the economy observed only states 3 or 4 for the Markov chain governing military expenditures and employment. On the basis of Hamilton's (1991) estimation procedure, these are the only states that occurred in the post-World War II period. Notice that the model predicts that participation is procyclical and that it fluctuates as much as output. In fact, for this parameterization the standard deviation is slightly larger for participation $p[t]$ than for output $y[t]$. Cho and Cooley (1994) and Kydland and Prescott (1991) have difficulty matching fluctuations in employment (or participation if there is no unemployment) with models that do not include government spending or home production. For example, Cho and Cooley (1994) report a quarterly standard deviation of $0.81 \%$ in employment for their model and a standard deviation of $1.5 \%$ for the U.S. data.

Including government spending and home production also leads to a much better 
match for hours per worker. In Cho and Rogerson (1988), hours per worker are constant because families in their model do not do homework and all variation in total hours is done along the extensive margin. The models of Cho and Cooley (1994) and Kydland and Prescott (1991) predict movement in hours per worker, but cannot capture the magnitudes observed in the data. For the simulation that generated Figure 4, we find a percent deviation of aggregate hours per worker equal to 1.2 percent. For the establishment survey data over the postwar, the percent deviation of aggregate hours per worker is equal to 1.29. As a comparison, note that Cho and Cooley understate this statistic by 46 percent.

If we look at fluctuations in hours for the different groups in the model, we find dramatic differences. The group with the smallest percent deviations $(0.265 \%)$ in hours are males with wives who work in the market and at home. The group with the largest percent deviations $(2.14 \%)$ are the wives of these men. Furthermore, the wives in these type- 1 families have the most variable home hours ( $1.09 \%$ as compared to $0.341 \%$ or $0.412 \%$ for other families).

We now turn to the predictions for wartime. To compare the model to data, we use the same sequence of states as plotted in Figure 1 for our Markov chain. Our intention is to get the timing of World War II correct. For this simulation, the model predicts that $p[t]$ would rise from $53 \%$ in 1939 to $64 \%$ in $1944 .^{7}$ Recall that $p[t]$ is the fraction of civilian families with wives working in the market. If we are interested in the fraction of civilians employed, we need $0.5(1+p[t])$. The model predicts that this fraction would rise from 0.767 in 1939 to 0.822 in 1944 , an increase of $7.2 \%$. The U.S. experienced an increase of about $12 \%$. For hours of work, which rose dramatically during the war, we find very different predictions for each group. The model predicts that hours for men in type-1 families, $h_{1 m}[t]$, would rise $5.6 \%$ between 1939 and 1944 . For their wives, the predicted increase in market hours is $36.5 \%$, which is significantly greater. They substitute home for market production during the war. On the other hand, the wives in type- 2 or type- 3 families adjust their hours only slightly, e.g., $2 \%$ or $3 \%$. For men in type- 2 families, the predicted increase is $18.1 \%$, which is close to the increase in average weekly hours observed in the U.S (19\%).

7 The level of $p[t]$ is high relative to actual figures in World War II but is in line with the postwar period. 


\section{Conclusions}

In both World War II and in the postwar period, the U.S. experienced large movements in employment and hours per worker. In this paper, we explore two possible sources for these movements: changes in military expenditures and changes in technology. We do so by developing a model of family labor supply. Our focus is on the family since a key to much of the cyclical patterns are the second earners in the family (e.g., wives).

The main differences between our model and other general equilibrium models of family labor supply are (a) government spending as a potential source of fluctuations and (b) home production in addition to market production. Our findings indicate that including both government spending and home production has a large impact on the model's predictions. Unlike earlier studies of employment and hours over the business cycle, we do not understate the magnitude of fluctuations in either series.

In this paper, we only consider labor supply over a business cycle or a period of large military expenditures and do not consider endogenous changes in the employment trends of men and women. The objective of this study was to determine how responsive is the family labor supply to technological change, both in the home and the market, and to changes in military spending and employment. We believe that both factors will be important for the study of labor market trends and the model developed here could be used as a starting point for such a study. 


\section{Data Appendix}

- private market consumption - consumption of nondurables, services and durables 1987 constant dollars from NIPA table 1.2, per capita.

- investment - fixed investment in 1987 constant dollars from NIPA table 1.2, per capita plus government investment constructed from the government capital series (see below) assuming a geometric depreciation rate.

- capital - nonresidential plus residential net stock of capital in constant 1987 dollars from Fixed, Reproducible Tangible Wealth 1925-1988 tables A6 and A16, per capita plus net stock of government owned and privately operated capital in constant 1987 dollars unpublished data from U.S. Dept. of Commerce, Bureau of Economic Analysis, per capita.

- government consumption - government purchases in constant 1987 dollars from NIPA table 1.2 net of government compensation of employees from NIPA table $3.8 \mathrm{a}$ and government investment, per capita.

- output - the sum of government consumption, government investment, private investment, and private consumption.

- working population- population 16 and over from U.S Historical Statistics from Colonial Times to 1970, p.10 updated using pan17 from Citibase.

- military employment - Military personnel on active duty divided by working population from U.S Historical Statistics from Colonial Times to 1970 series y904 updated using various issues of Statistical Abstract of the United States.

- civilian employment - Persons engaged in production from NIPA table 6.8A divided by working population net of fraction employed in the military.

- hours per worker - average weekly hours for production workers in manufacturing from U.S. Historical Statistics from Colonial Times to 1970 series D803 from 1929-1946, then from 1947 to 1985 Citibase series lphrm, average weekly hours for production workers in manufacturing from the establishment survey. This series was converted to a zero to one scale by multiplying by 48 (weeks worked per year) and then dividing by 4536 , the annual endowment of time. 


\section{Appendix A.}

Take $c_{1}(s)$ and $s$ as given. Find $c_{2}, c_{3}, h_{1 m}, h_{2 m}, h_{1 f}, n_{1}, n_{2}, n_{3}, k_{1 n}, k_{2 n}, k_{3 n}$, and $p$ that satisfy:

(A.1) $u_{1}\left(c_{2}, G\left(k_{2 n}, n_{2}\right)\right)-u_{1}\left(c_{1}(s), G\left(k_{1 n}, n_{1}\right)\right)=0$

$(A .2) \quad u_{1}\left(c_{3}, G\left(k_{3 n}, n_{3}\right)\right)-u_{1}\left(c_{1}(s), G\left(k_{1 n}, n_{1}\right)\right)=0$

(A.3) $v_{1}\left(h_{1 m}, h_{1 f}, n_{1}\right)-u_{1}\left(c_{1}(s), G\left(k_{1 n}, n_{1}\right)\right) z_{1} F_{2}\left(k_{m}, H_{m}\right)=0$

(A.4) $v_{1}\left(h_{2 m}, 0, n_{2}\right)-u_{1}\left(c_{1}(s), G\left(k_{1 n}, n_{1}\right)\right) z_{1} F_{2}\left(k_{m}, H_{m}\right)=0$

(A.5) $v_{2}\left(h_{1 m}, h_{1 f}, n_{1}\right)-u_{1}\left(c_{1}(s), G\left(k_{1 n}, n_{1}\right)\right) z_{3} z_{1} F_{2}\left(k_{m}, H_{m}\right)=0$

(A.6) $v_{3}\left(h_{1 m}, h_{1 f}, n_{1}\right)-u_{2}\left(c_{1}(s), G\left(k_{1 n}, n_{1}\right)\right) z_{2} G_{2}\left(k_{1 n}, n_{1}\right)=0$

(A.7) $v_{3}\left(h_{2 m}, 0, n_{2}\right)-u_{2}\left(c_{2}, G\left(k_{2 n}, n_{2}\right)\right) z_{2} G_{2}\left(k_{2 n}, n_{2}\right)=0$

(A.8) $v_{3}\left(0,0, n_{3}\right)-u_{2}\left(c_{3}, G\left(k_{3 n}, n_{3}\right)\right) z_{2} G_{2}\left(k_{3 n}, n_{3}\right)=0$

(A.9) $u_{1}\left(c_{1}(s), G\left(k_{1 n}, n_{1}\right)\right) z_{1} F_{1}\left(k_{m}, H_{m}\right)-u_{2}\left(c_{1}(s), G\left(k_{1 n}, n_{1}\right)\right) z_{2} G_{1}\left(k_{1 n}, n_{1}\right)=0$

(A.10) $u_{1}\left(c_{2}, G\left(k_{2 n}, n_{2}\right)\right) z_{1} F_{1}\left(k_{m}, H_{m}\right)-u_{2}\left(c_{2}, G\left(k_{2 n}, n_{2}\right)\right) z_{2} G_{1}\left(k_{2 n}, n_{2}\right)=0$

(A.11) $u_{1}\left(c_{3}, G\left(k_{3 n}, n_{3}\right)\right) z_{1} F_{1}\left(k_{m}, H_{m}\right)-u_{2}\left(c_{3}, G\left(k_{3 n}, n_{3}\right)\right) z_{2} G_{1}\left(k_{3 n}, n_{3}\right)=0$

(A.12) $2 u\left(c_{1}(s), G\left(k_{1 n}, n_{1}\right)\right)-v\left(h_{1 m}, h_{1 f}, n_{1}\right)-2 u\left(c_{2}, G\left(k_{2 n}, n_{2}\right)\right)+v\left(h_{2 m}, 0, n_{2}\right)$

$$
\begin{aligned}
& +u_{1}\left(c_{1}(s), G\left(k_{1 n}, n_{1}\right)\right)\left\{z_{1} F_{2}\left(k_{m}, H_{m}\right)\left(h_{1 m}+z_{3} h_{1 f}-h_{2 m}\right)\right. \\
& \left.-2\left(c_{1}(s)-c_{2}\right)-z_{1} F_{1}\left(k_{m}, H_{m}\right)\left(k_{1 n}-k_{2 n}\right)-\kappa^{\prime}(p)\right\}=0
\end{aligned}
$$

where $H_{m}=(1-a)\left(p h_{1 m}+z_{3} p h_{1 f}+(1-p) h_{2 m}\right), k_{m}=k-(1-a)\left(p k_{1 n}+(1-p) k_{2 n}\right)-$ $a k_{3 n}$, and $s=\left[k, z_{1}, z_{2}, z_{3}\right]$. 


\section{References}

Benhabib, Jess, Richard Rogerson, and Randall Wright. 1991. "Homework in macroeconomics: household production and aggregate fluctuations." Journal of Political Economy, 99: 1166-1187.

Braun, R. Anton and Ellen R. McGrattan. 1993. "The macroeconomics of war and peace," in O. Blanchard and S. Fischer (eds.), NBER Macroeconomics Annual. Cambridge: MIT Press.

Clark, Kim B. and Lawrence H. Summers. 1981. "Demographic differences in cyclical employment and variation." Journal of Human Resources, 16:61-79.

Cho, Jang-Ok and Thomas F. Cooley. 1994. "Employment and hours over the business cycle." Journal of Economic Dynamics and Control, 18:411-432.

Cho, Jang-Ok and Richard Rogerson. 1988. "Family labor supply and aggregate fluctuations." Journal of Monetary Economics, 21:233-245.

Greenwood, Jeremy and Zvi Hercowitz. 1991. "The allocation of capital and time over the business cycle." Journal of Political Economy, 99: 1188-1214.

Hamilton, James D. 1989. "A new approach to the economic analysis of nonstationary time series and the business cycle." Econometrica, 57:357-384.

Hamilton, James D. 1991. "State-space models," in R. Engle and D. McFadden (eds.), Handbook of Econometrics, Volume 4, forthcoming.

Killingsworth, Mark and James Heckman. 1986. "Female labor supply," in O. Ashenfelter and R. Layard (eds.), Handbook of Labor Economics, Volume 1. Amsterdam: NorthHolland.

Kydland, Finn E. and Edward C. Prescott. 1991. "Hours and employment variation in business cycle theory." Economic Theory, 1:63-81.

McGrattan, Ellen R. 1993. "Solving the stochastic growth model with a finite element method." Federal Reserve Bank of Minneapolis, Staff Paper \#164.

McGrattan, Ellen R., Richard Rogerson, and Randall Wright. 1993. "Household production and taxation in the stochastic growth model." Federal Reserve Bank of Minneapolis, Staff Paper \#166.

Milward, Alan S. 1977. War, Economy, and Society. Berkeley: University of California Press.

Morgan, James N. 1978. in G. Duncan and J. Morgan (eds.), Five Thousand American Families - Patterns of Economic Progress, Volume VI. Ann Arbor: Institute for Social Research.

Prescott, Edward C. 1986. "Theory ahead of business cycle measurement." CarnegieRochester Conference Series on Public Policy, 25:11-44. 


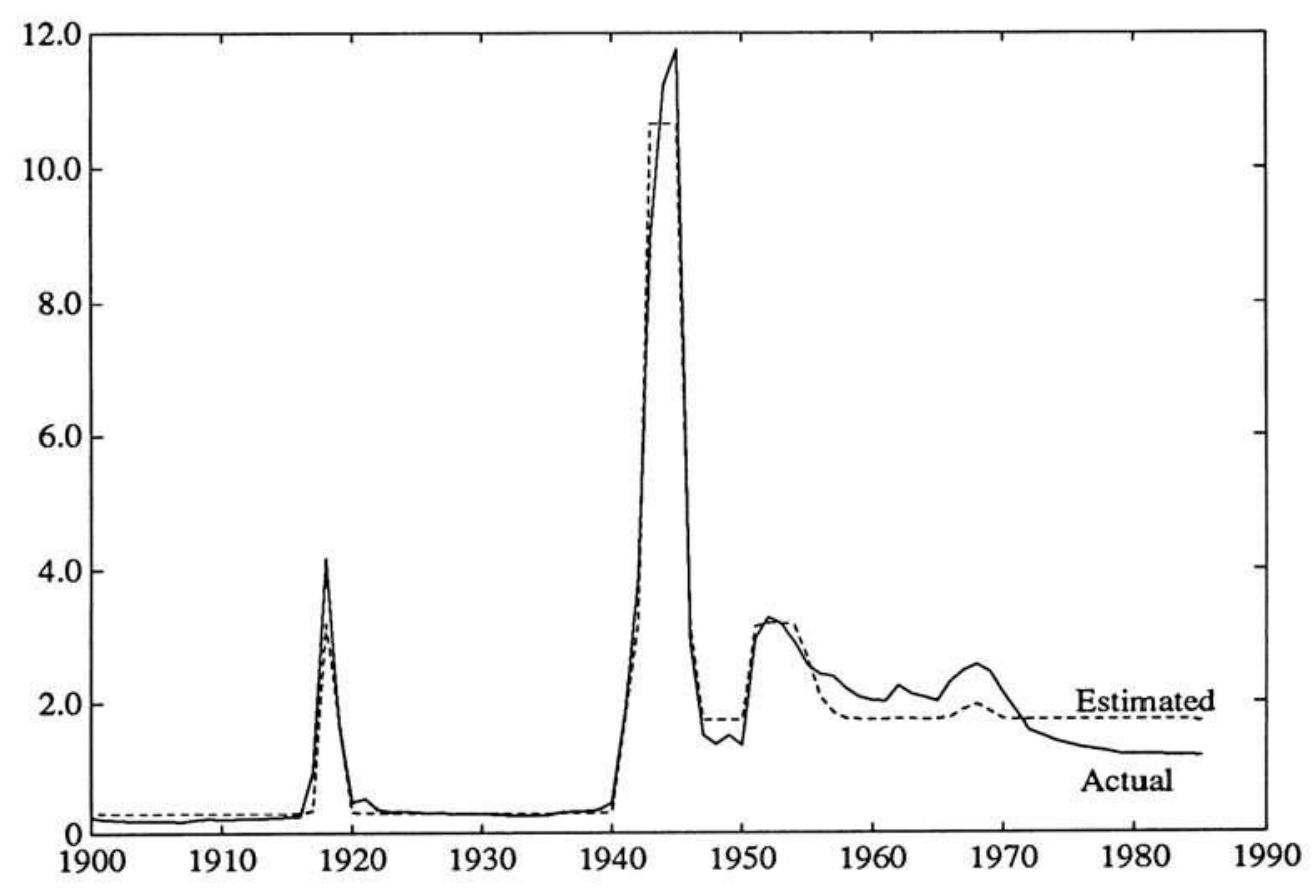

Figure 1. Estimates of 4-state Markov process for military employment. 
Table 1. MLE estimates of Markov process for military employment, 1900-1985.

\begin{tabular}{crrrrc}
\hline State & Mean $(\%)$ & \multicolumn{1}{c}{$\pi_{\cdot, 1}$} & \multicolumn{1}{c}{$\pi_{\cdot, 2}$} & \multicolumn{1}{c}{$\pi_{\cdot, 3}$} & $\pi_{\cdot, 4}$ \\
\hline 1 & 0.309 & 0.962 & 0 & 0.0187 & 0.020 \\
& $(0.068)$ & $(0.029)$ & & $(0.021)$ & \\
2 & 10.663 & 0 & 0.660 & 0 & 0.340 \\
& $(0.243)$ & & $(0.270)$ & & \\
3 & 1.732 & 0.043 & 0 & 0.895 & 0.061 \\
& $(0.0898)$ & $(0.033)$ & & $(0.057)$ & \\
4 & 3.187 & 0 & 0.115 & 0.401 & 0.485 \\
& $(0.268)$ & & $(0.114)$ & $(0.183)$ & \\
\hline
\end{tabular}

Standard errors in parentheses.

Table 2. Parameter estimates for preferences and technologies taken from McGrattan, Rogerson, Wright (1993). ${ }^{8}$

\begin{tabular}{llll}
\hline Description & Function & Parameter Estimates \\
\hline Utility function & $\begin{array}{c}2 \log (C)+b \log \left(1-h_{m}\right) \\
+b \log \left(1-h_{f}-n\right)\end{array}$ & $b=1.232$ & \\
& $\begin{array}{c}\left(a_{2} c^{b_{2}}+\left(1-a_{2}\right) x^{b_{2}}\right)^{\frac{1}{b_{2}}} \\
\text { Consumption }\end{array}$ & $a_{2}=0.485$ & $b_{2}=0.385$ \\
Home Output & $\left(a_{3} k_{n}^{b_{3}}+\left(1-a_{3}\right) h_{n}^{b_{3}}\right)^{\frac{1}{b_{3}}}$ & $a_{3}=0.210$ & $b_{3}=0.200$ \\
Market Output & $\left(a_{4} k_{m}^{b_{4}}+\left(1-a_{4}\right) h_{m}^{b_{4}}\right)^{\frac{1}{b_{4}}}$ & $a_{4}=0.234$ & $b_{4}=0.0525$ \\
\hline
\end{tabular}

8 We added $-d h_{m}\left(h_{f}+n\right)$ to the utility of families of type 1 to allow for complementarities in leisure. 


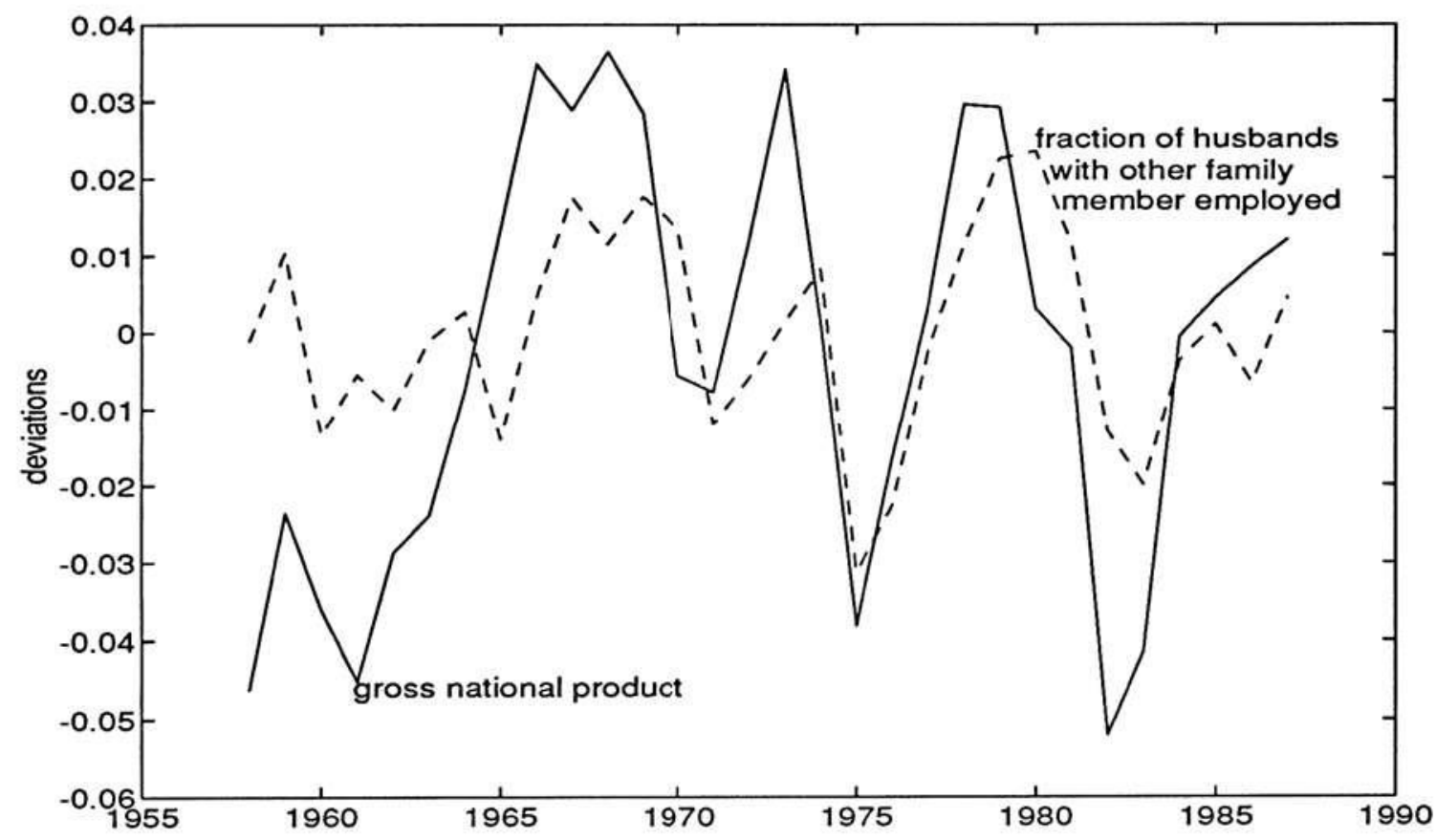

Figure 2. Percent deviations of U.S. GNP and the fraction of husbands who are employed with at least one other family member employed, 1958-1987.

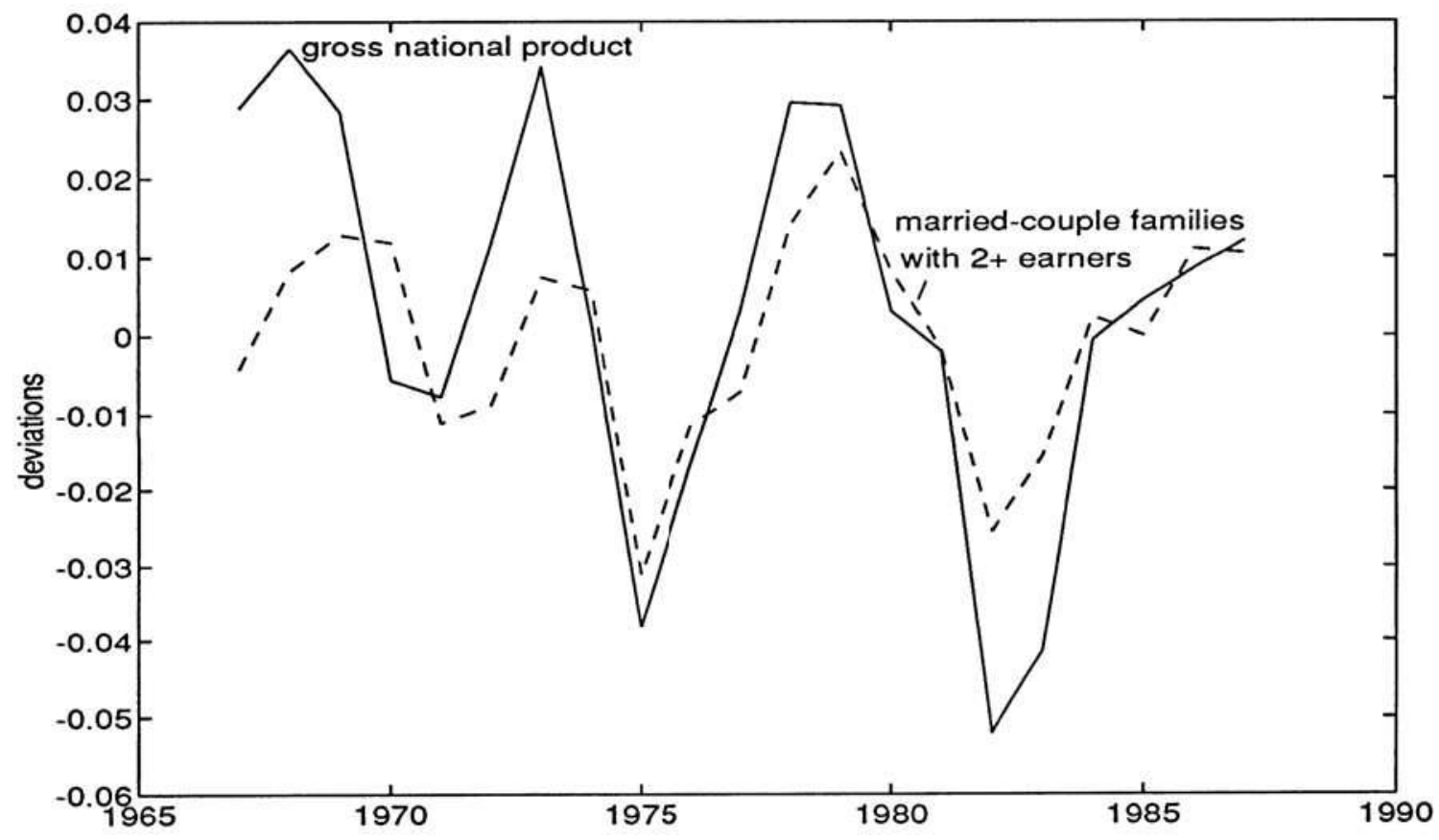

Figure 3. Percent deviations of U.S. GNP and the fraction of married-couple families with two or more earners, 1967-1987. 


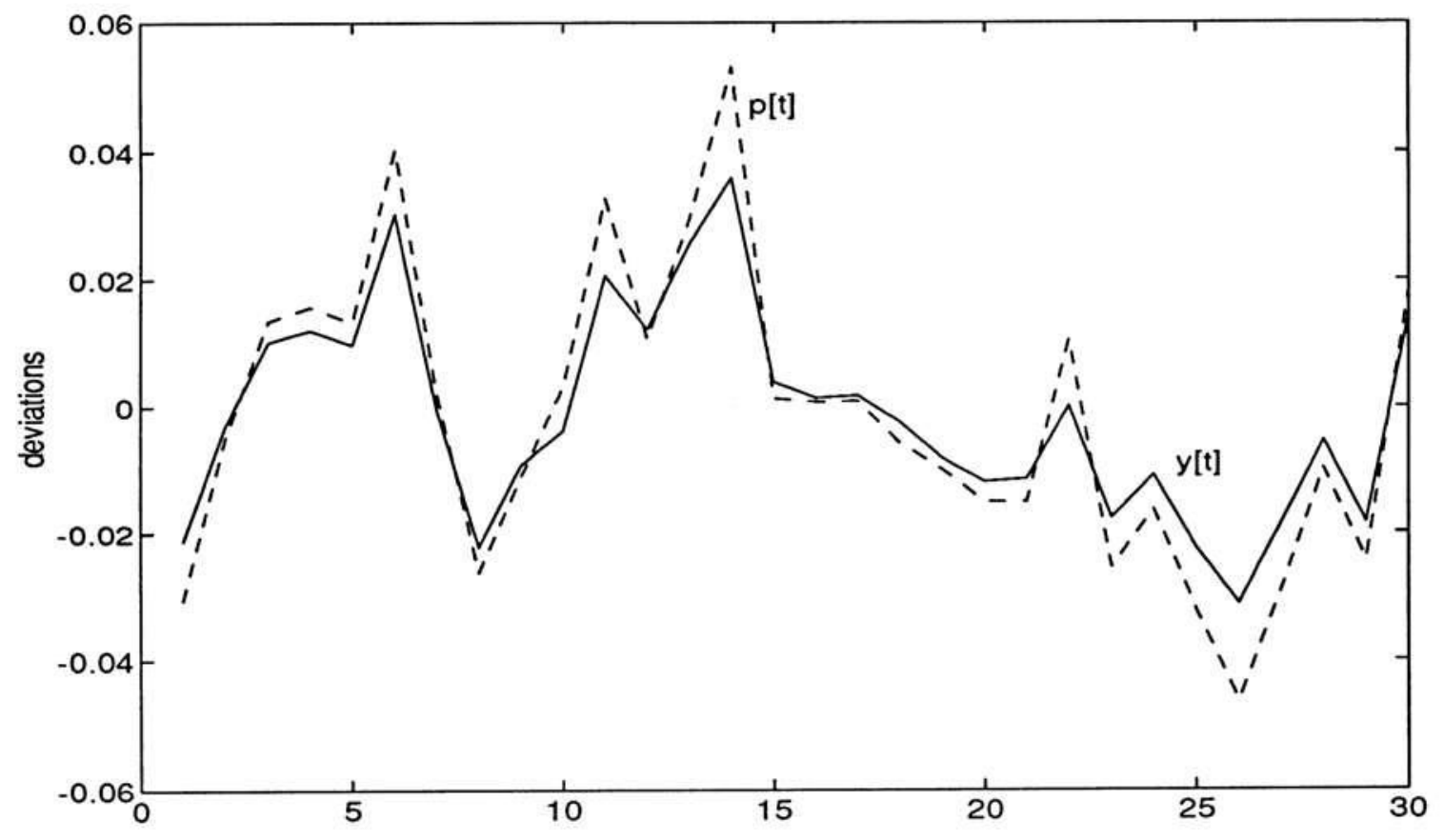

Figure 4. Percent deviations of model output and participation for 30 periods. 